\title{
NUTRITIONAL STATUS ASSESSMENT OF ORPHANAGE CHILDREN IN RAWALPINDI
}

\author{
Mehwish Riaz, Naila Azam, Humaira Mehmood*, Raima Asif, Nazish Khan*, Fatima Ali Raza Mughal \\ Foundation University, Islamabad Pakistan, *Armed Forces Post Graduate Medical Institute (AFPGMI)/National University of Medical Sciences (NUMS) \\ Rawalpindi Pakistan
}

\begin{abstract}
Objective: To evaluate the health and nutritional status of the orphanage, to find frequency of nutritional deficiencies by physical examination findings and to assess their dietary intake and contrast it with individual recommended daily allowances.

Study Design: Cross sectional study.

Place and Duration of Study: Four orphanages of Rawalpindi, from Jan to May 2020.

Methodology: Study was conducted at four orphanages of Rawalpindi on 276 children and adolescents. Children and adolescents in age group of 5-18 years and if they are resident of institution for more than 60 months were included in the study, while children who were extremely sick and mentally retarded were excluded from the study. Data was collected through questionnaire including demographic information, anthropometric assessment, nutritional deficiencies on physical examination and 24 hours food recall. Data was analyzed on SPSS 24.

Results: Results showed that 34 (17\%) children and adolescents were underweight, 99 (49.5\%) stunted, 21 (10.5\%) showed thinness and 9 (4.5\%) were overweight. Most common nutrient deficiency was protein calorie malnutrition, Iron deficiency and vitamin A and B 12 deficiency. Study population was consuming less protein, Iron and fats in diet as compared to recommended daily allowances.

Conclusion: Institutionalized children and adolescents are at risk of developing malnutrition due to financial constraints and ignorance of caregivers, which can lead to ill health of children. Programs are required to be undertaken for nutritional development of the orphanage children.
\end{abstract}

Keywords: Adolescents, Anthropometry, Malnutrition nutritional status, Orphanage, Under nutrition.

How to Cite This Article: Riaz M, Azam N, Mehmood H, Asif R, Khan N, Mughal FAR. Nutritional Status Assessment of Orphanage Children in Rawalpindi. Pak Armed Forces Med J 2021; 71(6): 2139-2143. Doi: https://doi.org/10.51253/pafmj.v71i6.6496

This is an Open Access article distributed under the terms of the Creative Commons Attribution License (https://creativecommons.org/licenses/by-nc/4.0/), which permits unrestricted use, distribution, and reproduction in any medium, provided the original work is properly cited.

\section{INTRODUCTION}

Nutritional assessment is an organized procedure of collection and interpretation of information for decision making regarding type and cause of nutrition related health issues. ${ }^{1}$ Assessment of nutrition has a cornerstone importance in children because growth retardation is mainly caused by under nutrition in childhood. ${ }^{2}$ In infancy and childhood, nutrition plays an important role in growth and development. In regard to children's need during early years of life, under-nutrition is mainly responsible for dietary deficiencies. ${ }^{3}$ Assessment of nutrition can be performed by using the $\mathrm{ABCDE}$ methods. They include Anthropometry, Biochemical/biophysical method, Clinical methods, Dietary method and Environmental factors. ${ }^{1}$

Malnutrition if not treated promptly can lead to stunted physical growth, disability and death, which will ultimately lead to hindrance to national socioeconomic development. ${ }^{4}$ Combination of dietary deficiencies mostly is the underlying cause of malnutrition, but

Correspondence: Dr Mehwish Riaz, Department of Community Medicine, Foundation University, Islamabad Pakistan

Received: 31 Mar 2021; revision received: 14 Jul 2021; accepted: 14 Jul 2021 acute infections may be a cause. ${ }^{5}$ Globally the magnitude of problem of malnutrition is intolerably high and progress is slow. Numerous issues are faced by children below five years of age: 150.8 million are stunted, 50.5 million are wasted and 38.3 million are overweight, ${ }^{6}$ According to National Nutrition Survey 2018 in children under 5 years of age prevalence of stunting was $40.2 \%$, wasting $17.7 \%$, underweight $28.9 \%$ and overweight were $9.5 \%$. While $53.7 \%$ children showed anemia due to nutritional deficiencies. It also depicts that adolescent girls were $11.8 \%$ underweight while $21.1 \%$ boys were under-weight. ${ }^{7}$

Worldwide there are nearly 153 million orphans, including 61 million in Asia ${ }^{8}$, while 4.2 million orphaned children are living in Pakistan. ${ }^{9}$ According to statistics of UNICEF, orphanages are home to at least 2.7 million children worldwide. ${ }^{10}$

The objective of the study was to evaluate the health and nutritional status of the orphanage, to find frequency of nutritional deficiencies by physical examination findings and to assess their dietary intake and contrast it with individual recommended daily allowances. 
Children and adolescents are essential asset of a country because they can take an essential role to provide the human potential required for its development. Malnutrition is the largest health problem of children in the developing countries especially among the orphans, this study will help to gain base line nutritional status of orphanages and necessary steps can be taken by authorities to prevent nutritional deficiencies to improve health of the children

\section{METHODOLOGY}

This cross sectional study was conducted at four registered orphanages of Rawalpindi, which were selected using consecutive sampling technique during January to May 2020. Sample size of 276 was calculated WHO sample size calculator by taking previous prevalence of underweight in orphanages of India as 55.7\% 11 , confidence interval $95 \%$ margin of error $5 \%$.

Inclusion Criteria: Children and adolescents of 5-18 years and if they are resident of institution for more than 60 months were included in the study.

Exclusion Criteria: Children who were extremely sick and mentally retarded were excluded from the study.

Study was approved by Ethical Review board of Foundation University (Ltr FF/FUMC/215-1/Phy/20). Approval of data collection was taken by concerned orphanage authority.

Data was collected by a structured questionnaire comprising of three sections. First section was based on demographic characteristics of participants such as age, gender, education, duration and reason for stay in orphanage. Second section included anthropometric measurements such as height, weight, mid upper arm circumference, BMI. Weight was calculated by digital body weight machine. Measurements were taken to the nearest 100 grams. Height was measured by stadiometer with bare foot in centimeters to nearest $1 \mathrm{~cm}$. Mid upper arm circumference was measured by Sharker's tape.

Third section included physical examination for nutritional deficiencies such as protein calorie malnutrition, Iron, vitamin C, vitamin A, B 12, D and iodine deficiency. Students of fourth year MBBS were trained for assessing nutritional deficiencies by physical examintation. ${ }^{24}$ hours food recall was used to assess their dietary patterns, menu of breakfast, lunch, snacks and dinner was interviewed, their nutritional value in terms of energy, proteins, carbohydrates, fats, Iron was calculated and compared with Recommended daily allowances.
Final sample size of 200 was achieved after cleaning out missing data information. Data was analyzed using Statistical Package for the social sciences (SPSS) version 22. Frequency and percentages were calculated for categorical variables. Mean \pm SD was calculated for quantitative variables. Weight for age, height for age and BMI for age was calculated from WHO Anthro plus software.

\section{RESULTS}

Final data of 200 children was analyzed. In Demographic characteristics of respondents $114(57 \%)$ were males, $122(61.0 \%)$ were in age group of 9-13 years, 116 (58\%) were having primary education, $78(39 \%)$ were living in orphanage for 1-3 years, $135(67.5 \%)$ reported death of parents as reason for living in orphanage as given in Table-I.

\begin{tabular}{l|c}
\multicolumn{2}{l}{ Table-I: Demographic characteristics of respondents. } \\
\hline Variables & $\mathbf{n}(\%)$ \\
\hline Gender & $114(57)$ \\
\hline Male & $86(43)$ \\
Female & \\
\hline Age of Respondent & $28(14)$ \\
\hline 4-8 years & $122(61)$ \\
9-13 years & $50(25)$ \\
14-18 years & \\
\hline Education & $116(58)$ \\
\hline Primary & $84(42)$ \\
Secondary & $135(67.5)$ \\
\hline Reason for Living in Orphanage & $55(27.5)$ \\
\hline Death of parents & $10(5)$ \\
Poverty & \\
Abandoned & $56(28)$ \\
\hline Duration of Living in Orphanage & $78(39)$ \\
\hline Less than 1 years & $66(33)$ \\
1-3 years & \\
More than 3 years & $49(24.5)$ \\
\hline Parent Died & $100(50)$ \\
\hline Mother & $17(8.5)$ \\
Father & $23(11.5)$ \\
Both & \\
None & \\
\hline
\end{tabular}

For nutritional deficiencies diagnosed on physical examination most prevalent deficiencies were protein calorie malnutrition 197 (98.5\%), anemia 74 (37\%), vitamin A deficiency $56(27.5 \%)$ and Vitamin B12 deficiency 69 (34.5\%) as shown in Table-II.

Anthropometric assessment was done and they were classified according to weight for age (underweight), height for age(stunting) and BMI for age (thinness). Thirity four $34(17 \%)$ were underweight, 99 $(49.5 \%)$ were stunted, $21(10.5 \%)$ had thinness and 9 (4.5\%) were overweight as shown in Table-III. 
Table-II: Frequency of nutritional deficiencies on physical examination.

\begin{tabular}{|c|c|}
\hline & n (\%) \\
\hline \multicolumn{2}{|l|}{ Protein Calorie Malnutrition } \\
\hline Thin Dyspigmented Hairs & $57(28.5)$ \\
\hline Moon face & $1(0.5)$ \\
\hline Decreased Subcutaneous Fat & $138(69.0)$ \\
\hline Edema & $1(0.5)$ \\
\hline \multicolumn{2}{|l|}{ Iron Deficiency } \\
\hline Pale Conjunctiva & $40(20.0)$ \\
\hline Koilonychia & $34(17.0)$ \\
\hline \multicolumn{2}{|l|}{ Vitamin A Deficiency } \\
\hline Bitot Spot & $52(26.0)$ \\
\hline Corneal Xerosis & $1(0.5)$ \\
\hline Skin Xerosis & $3(1.5)$ \\
\hline \multicolumn{2}{|l|}{ Vitamin C Deficiency } \\
\hline Bleeding and Swollen Gums & $21(10.5)$ \\
\hline \multicolumn{2}{|l|}{ Vitamin K Deficiency } \\
\hline Enlarged Thyroid Gland & $24(12.0)$ \\
\hline \multicolumn{2}{|l|}{ Vitamin B12 Deficiency } \\
\hline Loss of Ankle/Knee Jerk & $69(34.5)$ \\
\hline \multicolumn{2}{|l|}{ Vitamin D Deficiency } \\
\hline Bowed Legs & $3(1.5)$ \\
\hline
\end{tabular}

Table-III: Anthropometric measurements classification. Anthropometric Assessment of Children According To Weight For Age (Under Weight)

\begin{tabular}{l|c|c}
\hline & & $\mathrm{n}(\%)$ \\
\hline Normal & $>-1 S D$ to $<+1 S D$ & $166(83.0)$ \\
\hline Mild Underweight & $>-2 S D$ to $<-1 S D$ & $22(11.0)$ \\
\hline Moderate Under Weight & $>-3 S D$ to $<-2 S D$ & $10(5.0)$ \\
\hline Severe Underweight & $<-3 S D$ & $02(1.0)$ \\
\hline
\end{tabular}

Anthropometric Assessment of Children According To Height For Age(Stunting)

\begin{tabular}{l|c|c}
\hline Normal & $>-1 S D$ to $<+1 S D$ & $101(50.5)$ \\
\hline Mild Stunting & $>-2 S D$ to $<-1 S D$ & $55(27.5)$ \\
\hline Moderate Stunting & $>-3 S D$ to $<-2 S D$ & $29(14.5)$ \\
\hline Severe Stunting & $<-3 S D$ & $15(7.5)$ \\
\hline
\end{tabular}

Anthropometric Assessment of Children According To BMI For Age(Thinness)

\begin{tabular}{l|c|c}
\hline Normal & $>-1 S D$ to $<+1 S D$ & $170(85.0)$ \\
\hline Moderate Thinness & $>-3 S D$ to $<-2 S D$ & $18(9.0)$ \\
\hline Severe Thinness & s (<-3SD) & $3(1.5)$ \\
\hline Overweight & +1SD to +2SD & $9(4.5)$ \\
\hline
\end{tabular}

Table-IV: Macronutrients and micronutrients analysis of children diet (24 hours food recall).

\begin{tabular}{l|c|c}
\hline & Mean \pm SD & $\begin{array}{c}\text { Recommended } \\
\text { Daily Allowance }\end{array}$ \\
\hline Total energy (Kcal) & $1243.25 \pm 573.82$ & $1710-2820 \mathrm{Kcal}$ \\
\hline Protein $(\mathrm{gm})$ & $43.70 \pm 28.58$ & $30-66 \mathrm{gm}$ \\
\hline Carbohydrates $(\mathrm{gm})$ & $164.49 \pm 152.07$ & $130-150 \mathrm{gm}$ \\
\hline Fats $(\mathrm{gm})$ & $41.83 \pm 33.01$ & $44-70 \mathrm{gm}$ \\
\hline Total iron $(\mathrm{mg})$ & $10.46 \pm 18.05$ & $20-35$ \\
\hline
\end{tabular}

Study participants were asked for their dietary analysis by 24 hours food recall. They were inquired about their meal menu of breakfast, lunch, snacks and dinner. Amount of individual macro and micronu- trients was calculated and compared with RDA's. Their menu was found to be deficient in total calories, proteins, fats and iron as shown in Table-IV.

\section{DISCUSSION}

Pakistan is one of the countries whose population is increasing dramatically leading to increase in adolescent population and lack of resources are causing malnutrition in children and adolescents especially in low privileged situations.

In our study $114(57 \%)$ population were males in line with the study done by Ferdoushi 3 in which $50 \%$ children were males but study by Reddy, ${ }^{11}$ shows $80 \%$ males the difference might be due to different gender structure of study orphanages. Of $122(61 \%)$ children in age group of 9-13 years were present in this study which is in line with the study done by Ferdoushi 3 in which $63.5 \%$ children were in age group of years 9 143 but in contrast with the study done by Reddy 12 in which $68.3 \%$ were in age group $12-16$ years. Out fo $135(67 \%)$ reported reason for stay in hospital was death of parents it is almost according to study of by Ferdoushi 3 in which $71 \%$ reported death of parents as reason for stay in orphanage but in contrast in study done by Reddy 12 (47\%) children reported same reason. Regarding duration for stay in hospital, 39\% (78) reported it to be $1-3$ years and $100(50 \%)$ reported to be paternal orphan in accordance with study of Reddy 12 in which $39 \%$ showed duration of stay in hospital to be 1-3 years with $55.2 \%$ paternal orphans. For educational status, $58 \%$ were studying in primary classes this is accordance with study by Reddy. ${ }^{12}$

Weight for age classification in this study; 34 $(17 \%)$ children were underweight in which $11 \%$ children were mild underweight, $5 \%$ moderate underweight and 1\% severe underweight. A study in Ghana showed $10 \%$ children were underweight in orphanage. However, study by Ferdoushi et al showed 22.5\% were mild underweight, $10 \%$ were severely underweight and study by Reddy et al ${ }^{11}$ showed $32.3 \%$ were underweight. Reddy et al 12 showed $55.7 \%$ underweight in orphanage of Odisha, contrast in these studies might be due to better nutritional services provided in the orphanages. National Nutrition Survey 2018, ${ }^{10}$ showed the double burden of malnutrition is becoming increasingly apparent, with almost one in three children underweight $(28.9 \%)$ alongside a high prevalence of overweight $(9.5 \%)$ in the same age group while in adolescent age group $11.8 \%$ girls and $21.1 \%$ boys were underweight. 
In our study almost $49.5 \%$ (99) were stunting (mild, moderate and severe) in line with study by Ferdoushi $^{3}$ in which $56 \%$ children were stunted. Study by Reddy ${ }^{12}$ showed $51.9 \%$ children were stunted, this shows alarming situation of stunting in South East Asia, orphanage children are at risk of stunting due to nutritional deficiencies, previous stunting and infections. National nutrition survey 10 showed $40.2 \%$ children under 5 years are stunted while another study showed 10\% stunting in orphanage of Ghana et al from Ghana also reported $18.7 \%$ orphans were stunted. ${ }^{14}$

Regarding BMI for age 18 (9\%) had moderate thinness, $3(1.5 \%)$ had severe thinness while study done by Reddy 12 showed $25.2 \%$ thinness in study population which is in contrast with our study. Our study showed 9 (4.5\%) were overweight while NNS showed $10.2 \%$ boys and $11.4 \%$ girls were overweight. ${ }^{10}$ A study conducted by Farid in 2020 showed presence of malnutrition in $56(40 \%)$ normal and 76 (54.2\%) children with development delays. ${ }^{15}$ For nutritional status according to physical examination showed that $57(28.5 \%)$ had dyspigmented hairs, 138 (69\%) had decreased subcutaneous fat leading towards diagnosis of protein calorie malnutrition this is in contrast with previous studies in which $43.3 \%$ study population showed signs of protein deficiency. ${ }^{16,17}$

Seventy four $(37 \%)$ children and adolescents were found to be iron deficient on physical examination while National nutrition survey showed $56.6 \%$ adolescents were anemic which is far more than our study but in line with study Reddy ${ }^{12}$ in which $37 \%$ orphanage children were anemic.

Our study showed 12 (24\%) population was hypothyroid on physical examination while study by Jehanzeb showed 21 (37.5\%) children were hypothyroid on their biochemical examination. ${ }^{17}$

Study by Kassas showed 4 (2.6\%) children living in orphanage of North Lebanon, 18 had bowed legs while our study showed $3(1.5 \%)$ children had same issue.

Through 24-hour recollect method, it was found that orphan children's were consuming less energy, fats, proteins and iron with reference to RDA's. It was also found that on an average the orphans consumed $1243.2 \mathrm{kcal}$ energy instead RDA of 1710-2820 kcal. A previous study showed children living in orphanage of Ghana are also consuming less energy, fat, proteins, carbohydrates and micronutrients in their diet. ${ }^{18}$ Macro and micro nutrient deficit will lead to nutrition deficiencies which will ultimately cause growth impairment in children and adolescents. This nutrient deficit might be due to financial constraints and lack of awareness in caregivers and concerned authority regarding importance of dietary diversity.

Our results showed that $34(17 \%)$ children and adolescents were underweight, 99 (49.5\%) stunted, 21 $(10.5 \%)$ showed thinness and $9(4.5 \%)$ were overweight. Most common nutrient deficiency was protein calorie malnutrition, iron deficiency, and vitamin A and B12 deficiency. Study population was consuming less protein, energy, iron and fats in diet as compared to recommended RDA's. Institutionalized children and adolescents are at risk of developing malnutrition due to financial constraints and ignorance of caregivers, which can lead to ill health of children.Comprehensive nutrition programs are required to be undertaken for nutritional development of the orphanage children, which will in helps in early identification and timely intervention and will improve nutritional status of children living in orphanages.

\section{CONCLUSION}

Institutionalized children and adolescents are at risk of developing malnutrition due to financial constraints and ignorance of caregivers which can lead to ill health of children.

\section{Conflict of Interest: None.}

\section{Authors' Contribution}

MR: Direct contribution to conception of data, NA: Supervision of data, HM: Data collection, RA: Data anlaysis, NK: Interpretation of data, FARM: Proof reading.

\section{REFERENCES}

1. The British Association for Parenteral and Enteral Nutrition (BAPEN). Nutritional assessment. 2016 [Internet] Available at: https://www.bapen.org.uk/nutrition-support/assessment-andplanning/nutritional-assessment?showall

2. Yeganeh S, Niloofar M. Assessment of the knowledge and attitude of infants' mothers from Bushehr (Iran) on food security using anthropometric indicators in 2016: A cross-sectional study. BMC Public Health 2018; 18(1): 621-625.

3. Ferdoushi A, Rana MM, Mahmud MS, Datta D, Akter F .Health and Nutritional Status of the Selected Orphanage Children in Tangail City. Med 2014; 3(1): 11-15.

4. Kamath S, Venkatappa KG, Sparshadeep EM. Impact of nutritional status on cognition in institutionalized orphans: a Pilot Study. J Clin Diagn Res 2017; 11(3): CC01-CC04.

5. Global nutrition report. Global nutrition report. 2018 [Internet] Available at: https://globalnutritionreport.org/reports/globalnutrition-report-2018/executive-summary/ [Accessed on December 25, 2020]

6. UNICEF. Global Nutrition Report reveals malnutrition is unacceptably high and affects every country in the world, but there is also an unprecedented opportunity to end it. 2018, [Intenet] Available at: https://www.unicef.org/press-releases/2018global-nutrition-report-reveals-malnutrition-unacceptably-highand-affects [Accessed on January 3, 2021] 


\section{Orphanage Children}

7. UNICEF Pakistan. National Nutrition Survey 2018-Key Findings Report. 2020, Available at: https://www.unicef.org/pakistan/ reports/ national-nutrition-survey-2018-key-findings-report

8. One track International. Who is an orphan? 2019, [Internet] Available at: https://onetrackinternational.org/who-is-anorphan/ [Accessed on December 28, 2019]

9. UNICEF Pakistan. National Nutrition Survey 2018-Key Findings Report. [Internet] Available at: https://www.unicef.org/ pakistan/reports/national-nutrition-survey-2018-key-findingsreport (Accessed on December 30,2019)

10. World Health Organization. Publications. Nutrition. Adolescent Nutrition. A review of the situation in selected South-East Asian countries. 2006, [Internet]Available at: https://www.who.int/ nutrition/publications/schoolagechildren/ SEA_NUT_163/en/(Accessed on December 30,2019).

11. Reddy M, Ramya V. Morbidity profile of children residing in orphanages - A cross-sectional study in Chitradurga, Karnataka. Int J Med Sci Public Health. 2017; 6(7): 1196-1200.

12. Reddy SB, Jyothula N. Nutritional status and personal hygiene of children living in the orphanages of Bhubaneswar: capital city of Odisha. Int J Community Med Public Health 2019; 6(1): 379-385.
13. Reber E, Gomes F, Vasiloglou MF, Schuetz P, Stanga Z. Nutritional Risk Screening and Assessment. J Clin Med 2019; 8(7): 1065.

14. Ali Z, Abu N, Ankamah IA, Gyinde EA, Seidu AS, Abizari AK. Nutritional status and dietary diversity of orphan and nonorphan children under five years: a comparative study in the Brong Ahafo region of Ghana. BMC Nutr 2018; 4(2): 32.

15. Farid A, Maqbool S, Ullah E, Ali A, Farid Z. Risk factors in children presenting with developmental delay. Pak Armed Forces Med J 2020; 70(3): 812-817.

16. Lone MA. Health and nutritional status of orphan children's living in orphanages with special reference to district anantnag of Jammu and Kashmir. Int J Ind Psychol 2016; 3(2): 163-169.

17. Jehanzeb K, Ahmad F, Lodhi M, Ali S. Assessment of status of thyroid functions in patients of $\beta$ thalassemia major, reporting to OPD of military hospital, Rawalpindi. Pak Armed Forc Med J 2016; 66(6): 803-809.

18. El-Kassas G, Ziade F. The dual burden of malnutrition and associated dietary and lifestyle habits among lebanese school age children living in orphanages in north lebanon. J Nutr Metab 2017; 2: 4863431. 